\title{
Association of body-shape phenotypes with imaging measures of body composition in the UK Biobank cohort: relevance to colon cancer risk
}

Sofia Christakoudi ${ }^{1,2^{*}}$ (D, Konstantinos K. Tsilidis ${ }^{1,3}$, Evangelos Evangelou ${ }^{1,3}$ and Elio Riboli ${ }^{1}$

\begin{abstract}
Background: Body mass index (BMI), waist and hip circumference are strongly correlated and do not reflect body composition. A Body Shape Index (ABSI) and Hip Index (HI) define waist and hip size among individuals with the same weight and height and would thus reflect body density. We examined differences in body composition between body-shape phenotypes defined with ABSI and $\mathrm{HI}$ and used this information to propose explanations for associations between body-shape phenotypes and colon cancer risk.

Methods: We used data from the UK Biobank Resource for 15,520 men, 16,548 women with dual-emission X-ray absorptiometry (DXA) measurements; 3997 men, 4402 women with magnetic resonance imaging (MRI) measurements; 200,289 men, 230,326 women followed-up for colon cancer. We defined body-shape phenotypes as: large-ABSI-small-HI ("apple"), small-ABSI-large-HI ("pear"), small-ABSI-small-HI ("slim"), large-ABSI-large-HI ("wide"). We evaluated differences in body composition in linear models and associations with colon cancer risk in Cox proportional hazards models adjusted for confounders and explored heterogeneity by BMI.

Results: Among individuals with the same height and weight, visceral adipose tissue (VAT) was lowest for "pear" and highest for "apple", while abdominal subcutaneous adipose tissue (ASAT) was lowest for "slim" and highest for "wide" phenotype. In the gynoid region, differences between "apple" and "pear" phenotypes were accounted for mainly by fat mass in women but by lean mass in men. In men, lean mass was inversely associated with waist size, while the pattern of gynoid fat resembled ASAT in women. Lean and fat mass were higher for higher BMI, but not hand grip strength. Compared to normal weight "pear", the risk of colon cancer in men (1029 cases) was higher for "apple" phenotype for normal weight (hazard ratio HR $=1.77 ; 95 \%$ confidence interval: 1.16-2.69) and comparably for overweight and obese, higher for "wide" phenotype for overweight ( $H R=1.60 ; 1.14-2.24)$ and comparably for obese, but higher for "slim" phenotype only for obese ( $H R=1.98 ; 1.35-2.88)$. Associations with colon cancer risk in women (889 cases) were weaker.
\end{abstract}

\footnotetext{
* Correspondence: s.christakoudi@imperial.ac.uk

'Department of Epidemiology and Biostatistics, School of Public Health

Imperial College London, St Mary's Campus, Norfolk place, London W2 1PG, UK

${ }^{2}$ MRC Centre for Transplantation, King's College London, Great Maze Pond, London SE1 9RT, UK

Full list of author information is available at the end of the article
}

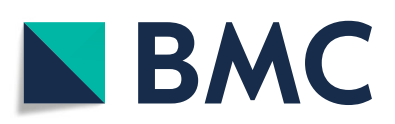

(- The Author(s). 2021 Open Access This article is licensed under a Creative Commons Attribution 4.0 International License, which permits use, sharing, adaptation, distribution and reproduction in any medium or format, as long as you give appropriate credit to the original author(s) and the source, provide a link to the Creative Commons licence, and indicate if changes were made. The images or other third party material in this article are included in the article's Creative Commons licence, unless indicated otherwise in a credit line to the material. If material is not included in the article's Creative Commons licence and your intended use is not permitted by statutory regulation or exceeds the permitted use, you will need to obtain permission directly from the copyright holder. To view a copy of this licence, visit http://creativecommons.org/licenses/by/4.0/. The Creative Commons Public Domain Dedication waiver (http://creativecommons.org/publicdomain/zero/1.0/) applies to the data made available in this article, unless otherwise stated in a credit line to the data. 
Conclusions: ABSI-by-HI body-shape phenotypes provide information for body composition. Colon cancer risk in men appears related to ASAT quantity for "slim" and "wide" but to factors determining VAT accumulation for "apple" phenotype.

\section{Background}

Excess body weight, as reflected in body mass index (BMI), is accepted as a risk factor for cardiovascular diseases and several cancers [1], but BMI cannot distinguish the contribution of fat and lean mass. Abdominal size is associated positively with the metabolic complications of obesity, while gluteofemoral size is associated inversely [2], but waist (WC) and hip circumference $(\mathrm{HC})$ are correlated strongly with each other and with BMI and cannot distinguish subcutaneous from visceral fat or lean from fat mass [3]. Although A Body Shape Index (ABSI) and Hip Index (HI) are also anthropometric indices, they are independent of weight and height by design and thus complement BMI $[4,5]$. In analogy to BMI, which compares body mass among individuals with the same height, ABSI and HI, which are related to body volume, compare the transversal body dimensions, waist and hip circumference, among individuals with the same weight and height. Positive associations with ABSI and inverse with $\mathrm{HI}$ have been reported for mortality, cardio-metabolic risk factors and various cancers, including several cancers which are not considered obesity related $[3,4,6,7]$.

We hypothesised that body-shape phenotypes defined with ABSI and HI would provide information for body composition as follows. Individuals with small-ABSIsmall-HI ("slim") would have the smallest volume for a given weight and height and would thus comprise body components with higher density, i.e. a larger proportion of lean mass. Individuals with large-ABSI-large-HI ("wide") would have the largest volume for a given weight and height and would thus comprise body components with lower density, i.e. a larger proportion of fat mass. Hence, there would be a density gradient between individuals with concordant ABSI and HI ("wide" vs "slim"). As the opposing metabolic effects of waist and hip size are mainly related to visceral fat [2], individuals with large-ABSI-small-HI ("apple") would have the largest visceral fat depot for a given weight and height, while individuals with small-ABSI-large-HI ("pear") would have the smallest visceral fat depot. Hence, there would be a visceral fat gradient between individuals with discordant ABSI and HI ("apple" vs "pear").

Using high-quality body-composition measurements from dual-emission X-ray absorptiometry (DXA) and magnetic resonance imaging (MRI) scans available for a subset of UK Biobank participants, we examined the body-composition profile of body-shape phenotypes defined with ABSI and $\mathrm{HI}$ and explored heterogeneity by BMI. To illustrate the relevance of this information to cancer epidemiology, we examined in the complete cohort the association between body-shape phenotypes and the risk of development of colon cancer, as the most common obesity-related cancer relevant to both men and women, for which we have already reported for UK Biobank positive associations with ABSI and BMI and, in men, an inverse association with HI [7].

\section{Methods \\ Study population}

UK Biobank comprises half a million participants from the general population in the United Kingdom (UK), with age at enrolment 40 to 70 years, who were recruited between 2006 and 2010 and have been followed-up prospectively $[8,9]$. In accordance with our previous studies in UK Biobank $[7,10]$, we restricted the study dataset to participants with self-reported white ancestry. To examine associations with body composition, we retained 32,068 participants with DXA measurement and 8399 with MRI measurements, excluding participants with missing imaging measurements, with anthropometric measurements which were extreme or missing at the imaging visit, with a mismatch between genetically determined and self-reported sex, younger than 45 or older than 75 at the imaging visit (to match the 30 years age window at enrolment and to minimise the influence of sarcopenia in the elderly), with prevalent cancer at the imaging visit, or with incident cancer or death within the first two years after the imaging visit (to minimise the influence of cancer cachexia). To examine associations with cancer risk, we excluded 71,873 participants with anthropometric measurements which were extreme or missing at enrolment, with a mismatch between genetically-determined and self-reported sex, younger than 40 or older than 70 years at enrolment, or with prevalent cancer at enrolment and pregnant women (Supplementary Fig. S1).

\section{Cancer ascertainment}

Cancer cases in UK Biobank are ascertained based on cancer registry linkage. The outcome of interest was first primary colon cancer diagnosed after enrolment, defined as in our previous publication with code $\mathrm{C} 18$ from the 
10th version of the International Classification of Diseases, and with behavioural code 3 or 5, excluding rare morphologies (histological codes 8240, 8241, 8243, 8245, $8246,8472,8743,8936,9680,9699)$ [7]. We censored at the date of diagnosis participants with first colon cancer with behavioural codes 6,9 , or missing, or with colon cancer with rare morphology (as stated above), or with first primary cancer with other location. We censored follow-up at 31st March 2016 (up to which date the cancer registry information was complete) for all participants who had remained cancer-free, or censored follow-up at the date of death, if this was earlier.

\section{Anthropometric indices}

Anthropometric measurements in UK biobank have been obtained by specifically trained technicians, at the natural indent or the umbilicus for waist circumference, and at the widest point for hip circumference [8]. To calculate ABSI for both sexes and HI for women, we used coefficients from the National Health and Nutrition Examination Survey (NHANES) [4, 5]. To calculate HI for men, we used simple-fraction coefficients based on UK Biobank data. HI calculated with coefficients from NHANES was uncorrelated with BMI in women but was inversely correlated with BMI in men from the UK Biobank cohort [7] and, similarly, in men from the European Prospective Investigation into Cancer and $\mathrm{Nu}$ trition (EPIC) cohort [3]. This suggests ethnic differences in HI, as $28 \%$ of NHANES participants had black ethnic background [5]. We have previously noted that the over-adjustment of hip circumference for weight and height observed in $\mathrm{HI}$ calculated with coefficients from NHANES can be corrected when ABSI, HI, BMI and height are examined in an additive model [7]. It was, however, important to avoid correlations with BMI when using $\mathrm{HI}$ as a free-standing index for cross-classification, as otherwise body-shape phenotypes would not be independent of body size. Calculating $\mathrm{HI}$ in men with coefficients from NHANES would have resulted in up to $40 \%$ differential misclassification with respect to BMI and $\mathrm{HI}$, with normal weight men with small HI ("slim and "apple" phenotypes) being misclassified as large $\mathrm{HI}$ and obese men with large HI ("pear" and "wide" phenotypes) being misclassified as small HI (Supplementary Table S1). To calculate the waist-to-hip index (WHI), we used the waist-to-hip ratio (WHR) and simple-fraction coefficients based on UK Biobank data [10]:

$$
\begin{aligned}
& \mathrm{ABSI}=\mathrm{WC}(\mathrm{mm}) * \mathrm{Weight}(\mathrm{kg})^{-2 / 3} * \operatorname{Height}(\mathrm{m})^{5 / 6} \\
& \mathrm{HI}_{\text {women }}=\mathrm{HC}(\mathrm{cm}) * \mathrm{Weight}(\mathrm{kg})^{-0.482} * \operatorname{Height}(\mathrm{cm})^{0.310} \\
& \mathrm{HI}_{\mathrm{men}}=\mathrm{HC}(\mathrm{cm}) * \mathrm{Weight}(\mathrm{kg})^{-2 / 5} * \operatorname{Height}(\mathrm{cm})^{1 / 5} \\
& \mathrm{WHI}=\mathrm{WHR} * W e i g h t(\mathrm{~kg})^{-1 / 4} * \operatorname{Height}(\mathrm{cm})^{1 / 2}
\end{aligned}
$$

$$
\mathrm{BMI}=\operatorname{Weight}(\mathrm{kg}) * \operatorname{Height}(\mathrm{m})^{-2}
$$

We dichotomised ABSI and HI using as cut-offs rounded numbers close to the sex-specific medians in the complete study dataset at enrolment: $\geq 73$ for women and $\geq 80$ for men for ABSI, $\geq 64$ for women and $\geq 49$ for men for HI. We categorised WHI in sex-specific quartiles and BMI in three groups according to the World Health Organisation cut-offs: normal weight (BMI $\geq 18.5$ and $\left.<25 \mathrm{~kg} / \mathrm{m}^{2}\right)$, overweight $\left(\mathrm{BMI} \geq 25\right.$ and $\left.<30 \mathrm{~kg} / \mathrm{m}^{2}\right)$ and obese (BMI $\geq 30$ and $\left.<45 \mathrm{~kg} / \mathrm{m}^{2}\right)$. Individuals with $\mathrm{BMI}<18.5$ and $\mathrm{BMI} \geq 45 \mathrm{~kg} / \mathrm{m}^{2}$ were excluded from the study, as they represented very small groups, which could have large leverage but could not be examined individually.

\section{Body-composition measurements}

Body-composition measurements were obtained on average 8.7 years after enrolment for DXA and 6.7 years for MRI. We used DXA measurements for regional lean and fat mass and compared these with bioelectrical impedance analysis (BIA) measurements obtained at the imaging visit. For visceral (VAT) and abdominal subcutaneous adipose tissue (ASAT), we compared DXA mass and MRI volume measurements. As an indicator of muscle functionality, we used hand grip strength [11].

Whole-body DXA images were acquired with GELunar iDXA scanner (GE Healthcare, Madison, Wisconsin, USA) and were analysed with GE enCORE software [12]. Regional fat and lean mass and VAT were available for a limited number of participants (2030 men and 2201 women). We used total regional mass and regional tissue fat percentage to calculate regional lean and fat mass for the complete DXA dataset (see details in Supplementary Methods). DXA regions were defined as follows: "arms" included the arms and shoulders areas; "trunk" included the neck, chest, abdominal and pelvic areas; "legs" included all remaining areas below the trunk; "android" overlapped the trunk region between the ribs and the pelvis; "gynoid" overlapped the legs and trunk regions, including the hips and upper thighs [13]. MRI images were acquired with a Siemens Aera $1.5 \mathrm{~T}$ scanner (Syngo MR D13) (Siemens, Erlangen, Germany), with a dual-echo Dixon Vibe protocol, and were analysed with AMRA profiler (Advanced MR Analytics, Linköping, Sweden) [14]. Measurements flagged with error codes by UK Biobank were considered missing. BIA measurements were obtained with Tanita BC-418MA Body Fat Analyser (Tanita Corp, Tokyo, Japan).

In analogy to allometric body-shape indices, we defined allometric body-composition indices. We scaled each body composition measurement with weight and height in a log-linear regression model: 
$\log ($ Measurement $) \sim \beta * \log ($ Weight $)+\gamma * \log ($ Height $)$

and then calculated an allometric index according to the formula:

$$
\text { Index }=\text { Measurement } * \text { Weight }^{-\beta} * \text { Height }^{-\gamma}
$$

To explore heterogeneity by BMI, we calculated allometric body-composition indices with scaling only for height. The scaling regression coefficients are listed in Supplementary Table S2.

\section{Statistical analysis}

We performed all analyses separately in men and women, because body shape and several cancers show substantial differences between sexes $[15,16]$.

To examine the association of body-shape phenotypes with body composition, we used body-composition indices as continuous variables, on the standardised scale of sex-specific $\mathrm{z}$-scores (value minus mean, divided by standard deviation, SD; see means and SD per index in Supplementary Table S2). We calculated pairwise partial Pearson correlation coefficients between body-shape and body-composition indices with adjustment for the main factors potentially influencing body size, body shape and body composition listed below. We further used multivariable linear regression models to calculate SD differences in body-composition indices between body-shape phenotypes ("pear"-reference," slim"," wide", "apple") defined according to an ABSI-by-HI cross-classification, adjusting for self-reported weight change within the last year preceding the imaging visit, smoking status, alcohol consumption, physical activity and age at the imaging visit, as well as Townsend deprivation index (available only at enrolment), region of the imaging assessment centre (for the DXA dataset) and in women also a combined variable including menopausal status and, for post-menopausal women, use of hormonal replacement therapy evaluated at the imaging visit (the definition of covariates is described in detail in Supplementary Methods). For comparison, we additionally examined the body-composition profile of WHI quartiles. To examine heterogeneity by body size, we examined the body-composition profile of an BMI-by-ABSI-by-HI cross-classification, using body-composition indices scaled only for height. We tested heterogeneity by BMI with a likelihood ratio test, comparing a model including ABSI-by-HI and BMI as separate categorical variables with a model including a BMI-by-ABSI-by-HI crossclassification variable.

To examine the association of body-shape phenotypes with colon cancer risk, we estimated hazard ratios (HR) and $95 \%$ confidence intervals (CI) with delayed-entry Cox proportional hazards models, stratified by age at enrolment and region of the initial assessment centre.
We used age as the underlying time scale, with the date of birth as origin, the date of attending an assessment centre at enrolment as the entry time, and the earliest of the date of diagnosis of the first incident colon cancer, or death, or date of censoring, as the exit time. All models were adjusted for height and potential confounders, as in the models examining bodycomposition indices as outcomes but evaluated at enrolment, and additionally for components of diet (consumption of vegetables and fresh fruit, fibre calculated according to [17], red meat, and processed meat), use of non-steroidal anti-inflammatory drugs, family history of cancer and, in women, age at the last live birth and use of oral contraceptives. Models for ABSI-by-HI were additionally adjusted for BMI. To explore possible reverse causality for cancer risk, we performed sensitivity analyses excluding participants with less than two years of follow-up. We additionally derived minimally adjusted HR estimates, with stratification by age and region and adjustment only for height and, for models with ABSI-by-HI, also for BMI, in order to explore the influence of covariates.

We used two-sided tests of statistical significance and considered $p<0.05$ as a weaker evidence and $p<0.001$ as a stronger evidence. Missing information for covariates was limited (Supplementary Table S3). To maximise sample size, we replaced missing values with the median category per sex. We used R version 4.0.5 for the linear regression models and STATA-13 for the Cox proportional hazards models $[18,19]$.

\section{Results}

\section{Cohort characteristics}

In total, 200,289 men and 230,326 women were included in the cancer risk dataset, 15,520 men and 16,548 women in the DXA body-composition dataset, and 3997 men and 4402 women in the MRI dataset. Mean BMI differed little between ABSI-by-HI body-shape phenotypes (up to $1.3 \mathrm{~kg} / \mathrm{m}^{2}$ ) (Table 1 ), compared to a difference of up to $8.1 \mathrm{~kg} / \mathrm{m}^{2}$ for body-shape phenotypes defined using WC-by-HC, which classified most participants with normal weight BMI as "slim" and most with obese BMI as "wide" phenotype (Supplementary Table S4). WHI was incremented between phenotypes in the order "pear"-"slim"-"wide"-"apple" (Table 1), with the first and fourth WHI quartiles overlapping substantially with "pear" and "apple" phenotypes but with all WHI quartiles contributing to "slim" and "wide" phenotypes (Supplementary Table S5).

Participants with "apple" phenotype were more likely to be current or former regular smokers, with higher Townsend deprivation index, using non-steroidal antiinflammatory drugs, consuming more red and processed meat but less fruit, vegetables and fibre, and less likely to 


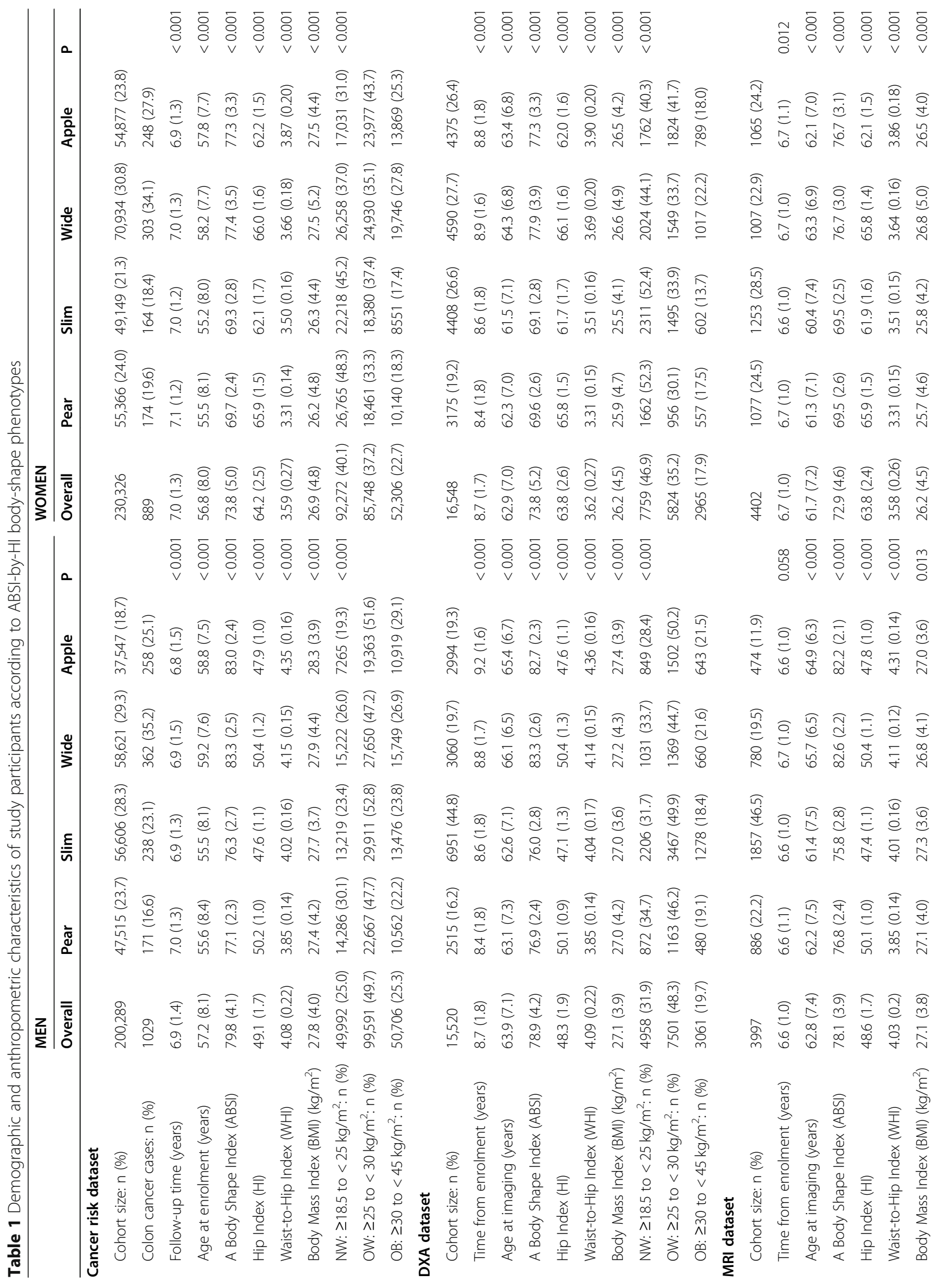




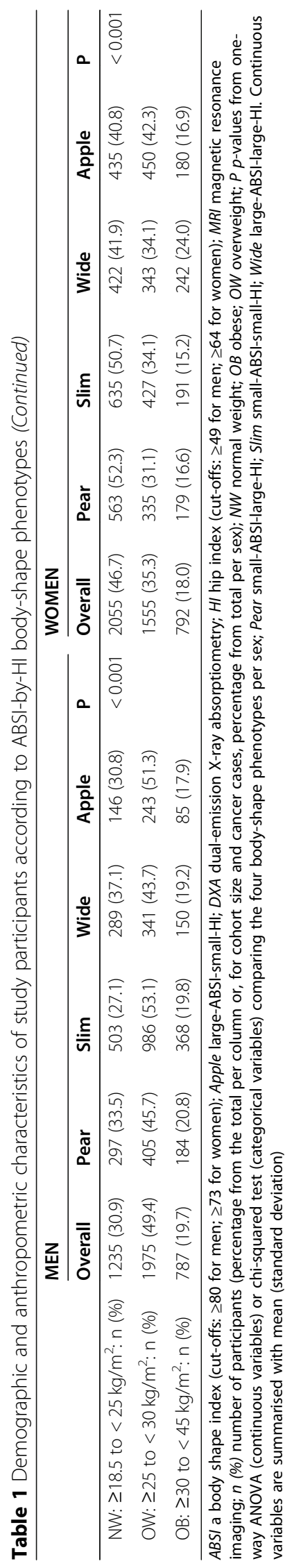




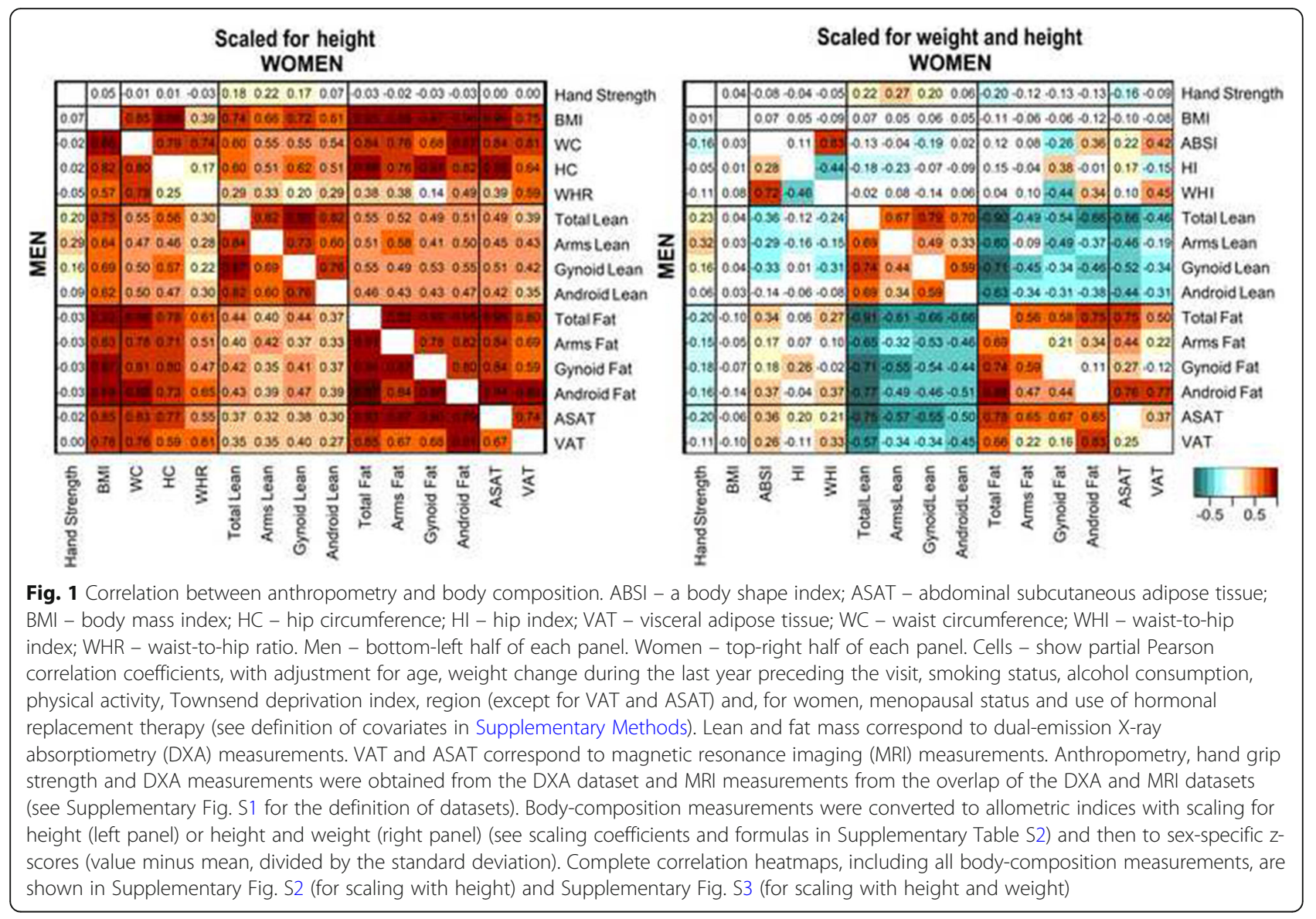

be physically active, with women also being more likely to have children at an earlier age, compared to participants with "pear" phenotype (Supplementary Table S3). Participants with "wide" phenotype were the oldest and least physically active, with women also being less likely ever users of oral contraceptives or current HRT users. Participants with "apple" and "wide" phenotypes were also more likely to have a family history of cancer and to consume alcohol daily. Participants with "slim" phenotype were the most physically active.

In the imaging datasets, BMI, ABSI and HI were lower compared to the cancer risk dataset and participants were less likely to have gained weight during the last year preceding the visit, to be smokers, daily alcohol consumers, physically inactive or, in women, ever HRT users, compared to the cancer risk dataset (Table 1, Supplementary Table S3).

\section{Correlation between anthropometry and body composition}

Among participants with the same height, all bodyshape and body-composition indices were positively correlated with each other and with BMI (Fig. 1, Supplementary Fig. S2). This included positive correlations between lean and fat mass in all regions and between VAT and gynoid fat mass, which are expected to be functionally different. Both WC and $\mathrm{HC}$ were positively correlated with lean and fat mass in the android and the gynoid regions.

The correlation patterns, however, differed considerably when participants were aligned by weight, in addition to height (Fig. 1, Supplementary Fig. S3). Lean mass was inversely correlated with fat mass in all regions. The correlations between VAT and gynoid fat mass were weak. In women, ABSI was correlated positively with android fat mass but not with android lean mass and was correlated inversely with gynoid lean and fat mass. In men, ABSI was correlated positively with fat mass (more strongly with android than with gynoid fat mass) and inversely with lean mass (more strongly with gynoid than with android lean mass). In both sexes, ABSI was correlated positively with VAT and ASAT, HI was correlated positively with gynoid fat mass and not with android fat mass overall, or with gynoid or android lean mass, but HI was correlated weakly positively with ASAT and inversely with VAT. Hand grip strength was weakly positively correlated with lean mass, most strongly for the arms. 


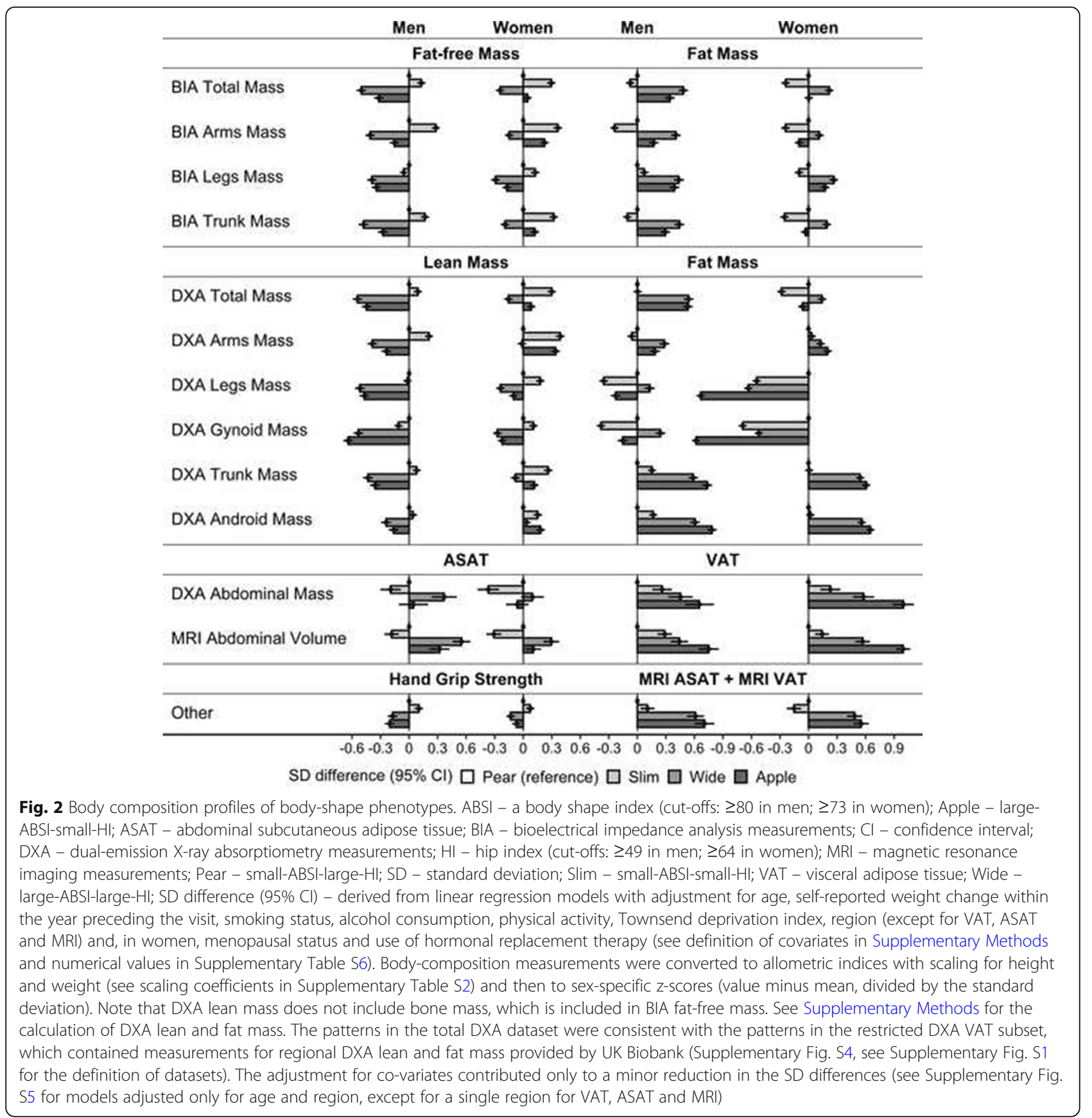

\section{Body-composition profile of body-shape phenotypes}

In the text below, we describe the patterns of lean and fat mass based on DXA and the patterns of VAT and ASAT based on MRI.

As hypothesised, total lean and fat mass differed between phenotypes with concordant waist and hip size in both sexes (Fig. 2). In women, differences in total fat and lean mass were maximised between "slim" and "wide" phenotypes, with the highest total lean mass for "slim" and the highest total fat mass for "wide" phenotype, but arms and android lean mass were inversely associated with hip size (highest for "slim" and "apple" phenotypes). In men, total and regional lean mass were inversely associated with waist size (lowest for "wide" and "apple" phenotypes), while total fat mass was associated positively with waist size (highest for "wide" and "apple" phenotypes). In both sexes, android fat mass overall was associated positively with waist size, but VAT was lowest for "pear" and highest for "apple" phenotype, while ASAT was lowest for "slim" and highest for "wide" phenotype, as hypothesised. The pattern of gynoid fat mass, however, differed substantially between men and women. In 


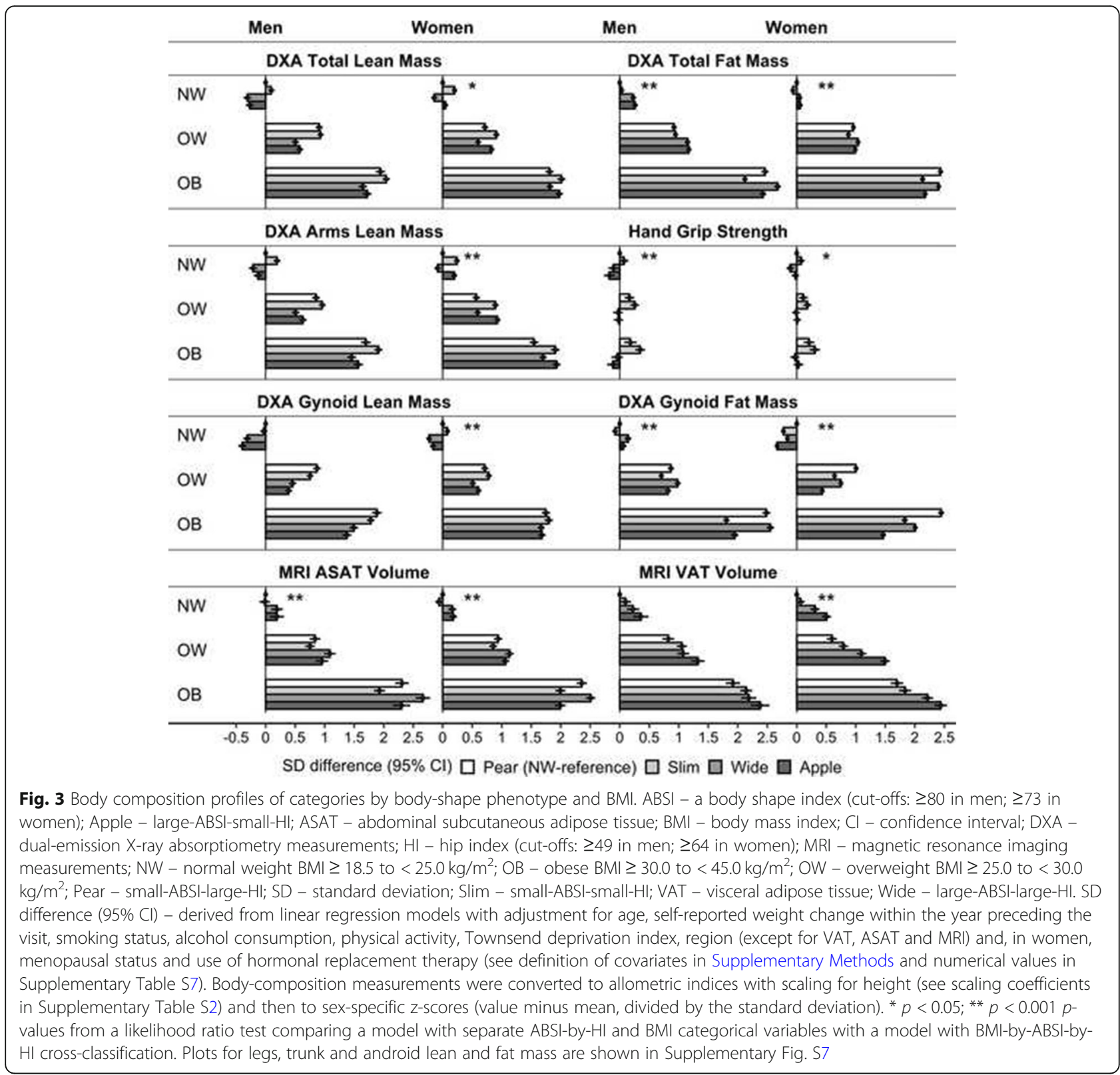

women, gynoid fat mass was lowest for "apple" and highest for "pear" phenotype while, in men, was lowest for "slim" and highest for "wide" phenotype. Consequently, the gynoid regions of "apple" and "pear" phenotypes differed mainly with respect to fat mass in women but with respect to lean mass in men. Associations of hand grip strength with body-shape phenotypes resembled the pattern of arms lean mass in men but of gynoid lean mass in women.

The patterns of VAT and ASAT based on DXA and MRI were in agreement (Fig. 2). Associations of bodyshape phenotypes with BIA indices, however, resembled DXA indices only for total lean and fat mass but differed substantially for individual regions, especially for fat mass (Fig. 2). For WHI quartiles, the VAT, ASAT, lean and fat mass gradients were overlapping, with the largest differences for all body-composition indices being between the lowest and the highest WHI quartile (Supplementary Fig. S6).

Combining BMI categories and body-shape phenotypes showed that lean as well as fat mass in all regions were higher for higher BMI, but higher lean mass was not paralleled by higher hand grip strength (Fig. 3). The patterns of gynoid lean mass and VAT were comparable among BMI categories. In women, gynoid fat mass was consistently lowest for "apple" and highest for "pear" phenotype in all BMI categories. In men, gynoid fat mass resembled the pattern of ASAT in women, with a 


\begin{tabular}{|c|c|c|c|c|c|c|}
\hline \multicolumn{2}{|r|}{ Men } & cases & HR $(95 \% \mathrm{Cl})$ & Women & cases & HR (95\% Cl) \\
\hline \multicolumn{2}{|c|}{ Overall } & $\begin{array}{l}171 \\
238 \\
362 \\
258\end{array}$ & $\begin{array}{c}\text { reference } \\
1.21(0.99 \text { to } 1.47) \\
1.27(1.06 \text { to } 1.53)^{\star} \\
1.48(1.21 \text { to } 1.80)^{\star *}\end{array}$ & & $\begin{array}{l}174 \\
164 \\
303 \\
248\end{array}$ & $\begin{array}{c}\text { reference } \\
1.11(0.90 \text { to } 1.38) \\
1.11(0.92 \text { to } 1.34) \\
1.24(1.02 \text { to } 1.51)^{\star}\end{array}$ \\
\hline \multicolumn{2}{|l|}{ NW } & $\begin{array}{l}42 \\
39 \\
66 \\
46\end{array}$ & $\begin{array}{c}\text { reference } \\
1.09(0.70 \text { to } 1.68) \\
1.14(0.77 \text { to } 1.68) \\
1.77(1.16 \text { to } 2.69)^{\star}\end{array}$ & & $\begin{array}{l}84 \\
58 \\
89 \\
76\end{array}$ & $\begin{array}{c}\text { reference } \\
0.88(0.63 \text { to } 1.22) \\
0.90(0.67 \text { to } 1.21) \\
1.25(0.91 \text { to } 1.70)\end{array}$ \\
\hline \multicolumn{2}{|l|}{ OW } & $\begin{array}{r}83 \\
116 \\
185 \\
127\end{array}$ & $\begin{array}{l}1.18(0.81 \text { to } 1.72) \\
1.28(0.90 \text { to } 1.83) \\
1.60(1.14 \text { to } 2.24)^{\star} \\
1.63(1.15 \text { to } 2.32)^{\star}\end{array}$ & & $\begin{array}{r}55 \\
68 \\
109 \\
120\end{array}$ & $\begin{array}{l}0.86(0.61 \text { to } 1.22) \\
1.12(0.81 \text { to } 1.55) \\
1.05(0.79 \text { to } 1.41) \\
1.28(0.97 \text { to } 1.71)\end{array}$ \\
\hline \multicolumn{2}{|l|}{$\mathrm{OB}$} & $\begin{array}{r}46 \\
83 \\
111 \\
85\end{array}$ & $\begin{array}{l}1.33(0.87 \text { to } 2.03) \\
1.98(1.35 \text { to } 2.88)^{* *} \\
1.69(1.17 \text { to } 2.42)^{\star} \\
1.99(1.37 \text { to } 2.91)^{\star *}\end{array}$ & $\sqrt{\beta}$ & $\begin{array}{r}35 \\
38 \\
105 \\
52\end{array}$ & $\begin{array}{l}1.01(0.67 \text { to } 1.50) \\
1.38(0.93 \text { to } 2.04) \\
1.32(0.98 \text { to } 1.78) \\
1.00(0.70 \text { to } 1.42)\end{array}$ \\
\hline \multicolumn{3}{|c|}{0.51 .01 .52 .02 .53 .0} & & 0.51 .01 .5 & & \\
\hline \multicolumn{7}{|c|}{ 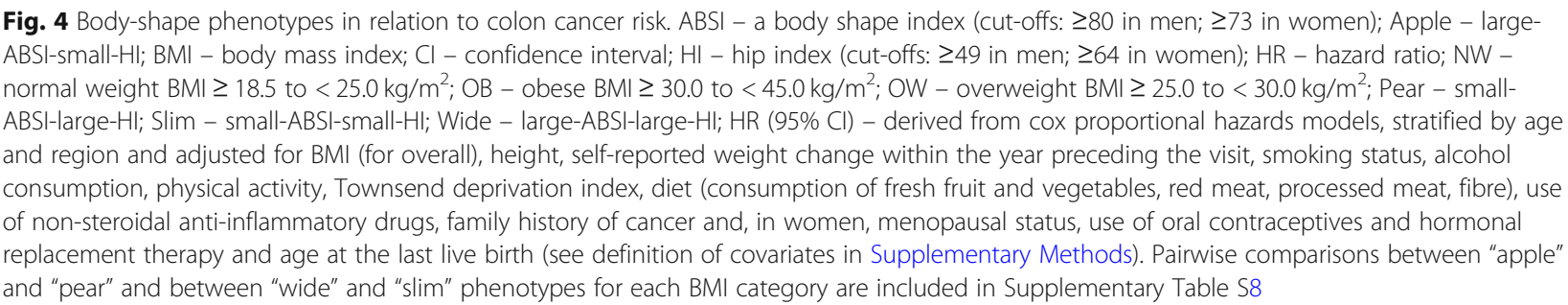 } \\
\hline
\end{tabular}

positive association with hip size in the obese BMI category (highest for "pear" and "wide" phenotypes). ASAT in men, however, showed a different pattern, with the lowest levels for "slim" and highest for "wide" phenotype in the obese BMI category.

\section{Associations of body-shape phenotypes with colon cancer risk}

During a mean follow up of seven years, 1029 colon cancers were ascertained in men and 889 in women.

In men, compared to "pear" phenotype, the risk was highest for "apple" ( $\mathrm{HR}=1.48,1.21$ to 1.80$)$ and intermediate for "slim" ( $H R=1.21,0.99$ to 1.47) and "wide" phenotypes ( $\mathrm{HR}=1.27,1.06$ to 1.53) (Fig. 4). Compared to normal weight BMI, the risk was incrementally higher for overweight $(\mathrm{HR}=1.18,1.00$ to 1.40) and obese BMI (HR $=1.43,1.19$ to 1.73) (Supplementary Table S8). In subsets by BMI and bodyshape phenotype, however, the risk was incrementally higher according to BMI only for "slim" and "wide" phenotypes. Using the normal weight "pear" phenotype as reference, the risk was higher in men with normal weight BMI only for "apple" phenotype (HR = $1.77,1.16$ to 2.69 ), additionally higher for "wide" phenotype in men with overweight BMI $(H R=1.60$, 1.14 to 2.24), and further additionally higher for "slim" phenotype in men with obese BMI $(\mathrm{HR}=1.98$, 1.35 to 2.88 ) (Fig. 4). The risk for "apple" phenotype remained higher compared to "pear" phenotype for all BMI categories but without a marked increment for higher BMI categories (Supplementary Table S8).

In women, associations were weaker compared to men. The risk was higher for "apple" compared to "pear" phenotype overall ( $\mathrm{HR}=1.24,1.02$ to 1.51 ), and most clearly in women with overweight $\mathrm{BMI}(\mathrm{HR}=1.49,1.08$ to 2.05) but not in women with obese BMI, while for "slim" and "wide" phenotypes, there was a suggestion for a positive association only in women with obese BMI (Fig. 4, Supplementary Table S8).

In sensitivity analyses, associations with colon cancer were stronger when omitting the adjustment with covariates but the patterns remained consistent after removing participants with less than two years of follow-up, albeit with a major loss of power (Supplementary Fig. S8). 


\section{Discussion}

Our study has shown that, among individuals with the same height and weight, VAT differences were maximised between body-shape phenotypes with discordant waist and hip size (lowest for "pear" and highest for "apple" phenotype), while ASAT differences were maximised between body-shape phenotypes with concordant waist and hip size (lowest for "slim" and highest for "wide" phenotype). In the gynoid region, "apple" and "pear" phenotypes differed mainly by fat mass in women but by lean mass in men, with fat mass contributing in men only at obese BMI. Lean similarly to fat mass was higher for higher BMI but was not paralleled by higher hand grip strength. In men, lean mass was inversely associated with waist size. Compared to normal weight "pear" phenotype, the risk of colon cancer in men was comparably higher for "apple" phenotype in all BMI categories, for "wide" phenotype only for overweight and obese BMI and for "slim" phenotype only for obese BMI. Associations with colon cancer in women were weaker.

Our study is the first to define body-shape phenotypes combining ABSI and $\mathrm{HI}$, to examine their association with body composition using high-quality imaging measurements and to explore heterogeneity by BMI. Several small-scale studies have previously reported, in agreement with our findings, a positive association of ABSI with VAT assessed with BIA [20] or computer tomography [21] and inverse associations of ABSI with hand grip strength [22] and with total fat-free mass assessed with BIA [23, 24] or DXA [21, 25]. Our study, however, has shown that ABSI-by-HI body-shape phenotypes are more informative for body composition than ABSI and HI used individually. Using ABSI alone would not discriminate VAT from ASAT, as ABSI was correlated positively with both, but combining ABSI with HI would enable a discrimination between VAT and ASAT, as VAT and ASAT differences were maximised between non-overlapping pairs of body-shape phenotypes. Further, our study indicates that the higher lean mass corresponding to higher BMI reflects mainly the energy storage capacity of the muscles, as higher lean mass was not matched by correspondingly higher functionality measured with hand grip strength. In agreement, muscles represent the main glycogen storage depot [26] and intervention studies have reported an increase of both lean and fat mass after overfeeding [27]. In our study, we have also compared DXA and BIA measurements of regional fat and lean mass and DXA with MRI measurements of VAT and ASAT with respect to their associations with body-shape phenotypes. DXA has previously shown good agreement with MRI and computer tomography, including for VAT measurement [28], although DXA lean mass is quantified indirectly and could be influenced by body hydration and overestimated in obesity
$[29,30]$. BIA, however, additionally overestimates fatfree mass in obesity compared to DXA and, most importantly, is disproportionately sensitive to limb and trunk water content [31-33]. Accordingly, our study has demonstrated that BIA does not agree with DXA for regional body composition, which is more relevant to the detrimental consequences of obesity.

Positive associations of the traditional indices of abdominal obesity WC and WHR, as well as BMI, with colon cancer risk, stronger in men than in women, have previously been reported [34], but hip size has not been considered. Large prospective studies examining associations between regional body composition and colon cancer risk are also lacking, although small-scale studies, mainly with case-control design, have reported positive associations with VAT [35]. Recent studies in UK Biobank have also reported for men positive associations with BIA total fat and BIA fat-free mass [36, 37], when examined individually, but only with BIA fat mass when mutually adjusted [36]. The opposition of lean and fat mass and their mutual adjustment, however, do not account for their relatedness as excess energy depots and we have previously demonstrated that combining correlated obesity indices results in biased risk estimates [3, 7]. When we examined BMI, waist and hip circumference were individually, all three were associated positively with colon cancer risk in men [7]. Mutually adjusting all three in the same model converted the positive association with hip circumference to inverse, in agreement with the inverse association with $\mathrm{HI}$, but also abolished the positive association with BMI, which remained independent of adjustment for ABSI and HI [7]. We have also previously demonstrated that using a waist circumference index strongly correlated with BMI does not permit risk stratification by waist size independent of body size, as this classifies as high risk only a very small group of individuals with low BMI and most individuals with high BMI [3]. In the current study, we have similarly shown that it is not possible to use waist and hip circumference to define body-shape phenotypes independent of body size. We would, therefore, advocate replacing waist and hip circumference with ABSI and HI in studies examining associations with body shape.

The body-composition profiles of body-shape phenotypes would likely be explained, to a great extent, by glucocorticoids and sex-steroids, which are interrelated [15, 38-40]. Cortisol contributes to lean mass reduction by reducing insulin sensitivity and inhibition of glycogen accumulation in skeletal muscles $[41,42]$. Correspondingly, high cortisol in patients with Cushing's syndrome leads to muscle mass reduction and VAT increase, which are ameliorated after adrenalectomy [43, 44]. In men, testosterone has opposite effects to cortisol and glucocorticoid excess suppresses testosterone production 
$[45,46]$. Low testosterone levels in men are associated with higher waist circumference and sarcopenia [47, 48], while testosterone supplementation in hypogonadal men increases muscle mass and reduces VAT $[49,50]$ and ABSI [21]. VAT reduction, however, requires aromatisation of testosterone to oestradiol [51]. In women, androgens have a different relationship with obesity and VAT. Serum levels of free testosterone are higher in women with abdominal obesity [52] and testosterone administration in female-to-male transsexual conversion increases VAT [53]. In both sexes, morbid obesity contributes to a dysfunction of the hypothalamuspituitary-gonadal axis, which is alleviated by bariatric surgery, with a resulting increase of testosterone in men and a decrease in women [54].

Oestrogen effects on body composition are also sexually dimorphic and related to glucocorticoids. Thus in women, abdominal obesity and liver steatosis develop after the menopause following a decrease of blood oestrogen levels and oestrogen receptor (ER $\alpha)$ expression in adipose tissue [55-57]. Mouse models have shown that VAT mass gain after ER $\alpha$ reduction in adipocytes is female-specific [58] and the development of liver steatosis after oestrogen reduction is dependent on hypersensitisation of the glucocorticoid receptor [59]. Further, administration of oestrogens combined with the antiandrogen cyproterone acetate in post-menopausal women increases subcutaneous fat specifically in the legs [60], while in male-to-female transsexual conversion the same combination increases subcutaneous fat in both the abdominal and hip areas [53].

Associations of body-shape phenotypes with a given outcome may either be mediated via body composition or may be determined directly by the mechanistic pathways regulating regional body size and composition. If regional fat depots are involved, the outcome would be associated positively with BMI, as fat mass in all regions is higher for higher BMI. In our study, colon cancer risk was positively associated with BMI mainly in men with concordant waist and hip size ("slim" and "wide"). There was also an apparent dependence on critical mass accumulation and a saturation, as compared to normal weight "pear" phenotype, the risk for "wide" phenotype was similarly higher for overweight and obese BMI. This would be compatible with a receptor-mediated mechanism, dependent on higher ligand supply with depot expansion but limited by receptor saturation. Although ASAT was higher for higher BMI, ASAT was consistently lowest for "slim" and highest for "wide" phenotype at any BMI. ASAT would thus reach the critical mass at lower BMI for "wide" phenotype but at higher BMI for "slim" phenotype, thus explaining the higher risk for "slim" phenotype only for obese BMI. A critical mass effect, requiring lowering of BMI below a critical point, may also explain why weight reduction examined on a continuous scale was not associated with a reduction in colon cancer risk [61]. Oestrogens derived from androgen aromatisation in ASAT would be one potential candidate for a ligand, as colon cancer cells appear to favour oestradiol, synthesising it locally via their own aromatase activity [62] and expressing higher levels of $E R \alpha$, which promotes cell proliferation [63]. Other ligands originating from ASAT such as adipokines, however, may also contribute to the observed associations.

In men with discordant waist and hip size, colon cancer risk appeared related more to the factors determining body shape and less to mass quantity, as the risk was similarly higher for "apple" compared to "pear" phenotype in all BMI categories. Given that "apple" and "pear" phenotypes differed mainly with respect to VAT, we propose that in men with discordant waist and hip size colon cancer is associated primarily with factors determining VAT quantity. Cortisol could be one such factor, as colon cancer cells can synthesise it locally and use it to mediate tumour immune escape via suppression of $\mathrm{T}$ cell activation [64]. Cortisol also stimulates colon cancer cell growth in vitro [65]. The mechanism, however, is likely to be more complicated, involving other interrelated factors such as sex-steroids, insulin resistance, and chronic inflammation and this would need to be clarified in future studies. In any case, our study suggests that a weight reduction without body-shape alteration is unlikely to achieve colon cancer risk reduction for "apple" phenotype in men. Although at present there is no simple answer how to modify body shape, it would be important to ensure that men with "apple" phenotype adhere rigorously to colon cancer screening programs. It would also be important to clarify in future studies how interventions such as modification of diet, hormonal replacement therapy, or physical activity can alter beneficially body shape, although in the case of hormonal therapy, any benefits would have to be balanced against potential risks of hormone-related cancers.

A strength of our study is the sizeable number of participants with body composition measurements and incident colon cancers, which provided statistical power and permitted examining men and women separately. Body composition measurements were obtained with high-quality imaging techniques. Anthropometric measurements were obtained by trained personnel, avoiding bias from selfreported values. Models were adjusted for major lifestyle factors, minimising confounding. However, due to lack of adequate data, we could not examine directly associations between body composition and cancer risk, or ethnic variations in body composition, which are known to be large $[13,66]$, or heterogeneity by menopausal status (there were no younger pre-menopausal women in the imaging datasets), or heterogeneity by obesity grade, or extreme 
obesity, or longitudinal changes in time. Furthermore, UK Biobank participants are not representative of the overall population [67]. This discrepancy was even more prominent for participants in the imaging datasets, which were less obese and with healthier lifestyles than the cohort at enrolment.

\section{Conclusion}

While BMI provides information for the quantity of fat and lean mass overall, ABSI-by-HI body-shape phenotypes provide information for body composition, reflecting differences between VAT and ASAT and between gynoid lean and fat mass among individuals with the same weight and height. Our results are compatible with a leading contribution of gynoid fat to differences in hip size in women but suggest a different role and regulation of gynoid fat in men, possibly similar to ASAT in women. Body-shape phenotypes show differences in body composition at all BMI levels and convey information for a separate aspect of obesity, independent from energy balance. Colon cancer risk in men is lowest in "pear" phenotype and appears related to ASAT quantity for "slim" and "wide" phenotypes but to factors determining VAT accumulation for "apple" phenotype. Examining associations with body-shape phenotypes in addition to associations with BMI would enhance studies of obesity related outcomes. We would recommend using the ABSI-by-HI body-shape phenotypes and the BMI-by-ABSI-by-HI cross-classification in studies examining obesity and cancer risk to obtain risk stratification by body shape independent of body size, as well as to provide insights for associations with body composition and hypotheses for future investigation.

\section{Abbreviations}

ABSI: A body shape index; BIA: Bioelectric impedance analysis; BMI: Body mass index; Cl: Confidence interval; DXA: Dual-emission X-ray absorptiometry; HC: Hip circumference; HI: Hip index; HR: Hazard ratio; MRI: Magnetic resonance imaging; NHANES: National Health and Nutrition Examination Survey; SD: Standard deviation; UK: United Kingdom; WC: Waist circumference; WHI: Waist-to-hip index; WHR: Waist-to-hip ratio

\section{Supplementary Information}

The online version contains supplementary material available at https://doi. org/10.1186/s12885-021-08820-6.

\section{Additional file 1.}

\section{Acknowledgements}

Not applicable.

\section{Authors' contributions}

SC, KK and ER conceived and designed the study. SC led the research and performed the statistical analysis. SC had full access to all of the data in this study and takes responsibility for the integrity of the data and the accuracy of the data analysis. SC drafted the paper with contributions from EE, KKT and ER. All authors, i.e. SC, EE, ER and KKT were involved in the interpretation of the results and the critical revisions of the paper. All authors have read and approved the manuscript.

\section{Funding}

This work was supported by the National Institute for Health Research (NIHR) Imperial Biomedical Research Centre (BRC), which provided infrastructure support for the Department of Epidemiology and Biostatistics at Imperial College London (UK). The funder had no role in the design and conduct of the study, the collection, analysis, and interpretation of the data, or the preparation, review, and approval of the manuscript, or in the decision to submit the manuscript for publication.

\section{Availability of data and materials}

The data supporting the findings of the study are available to bona fide researchers upon approval of an application to the UK Biobank (https://www. ukbiobank.ac.uk/researchers/) and a material transfer agreement.

\section{Declarations}

Ethics approval and consent to participate

The UK Biobank cohort has been approved by the North West Multicenter Research Ethics Committee, UK (Ref. Number: 16/NW/0274). Written informed consent has been obtained from all study participants. The current study was approved by the UK Biobank access management board. This research was conducted using the UK Biobank Resource (https://www.ukbiobank.ac. uk/about-biobank-uk/) under Application number 41952, granting access to the corresponding data.

\section{Consent for publication}

Not applicable.

\section{Competing interests}

The authors declare that they have no competing interests.

\section{Author details}

${ }^{1}$ Department of Epidemiology and Biostatistics, School of Public Health, Imperial College London, St Mary's Campus, Norfolk place, London W2 1PG, UK. ${ }^{2}$ MRC Centre for Transplantation, King's College London, Great Maze Pond, London SE1 9RT, UK. 'Department of Hygiene and Epidemiology, University of loannina School of Medicine, loannina, Greece.

Received: 11 July 2021 Accepted: 30 September 2021

Published online: 15 October 2021

\section{References}

1. Lauby-Secretan B, Scoccianti C, Loomis D, Grosse Y, Bianchini F, Straif K. Body fatness and Cancer--viewpoint of the IARC working group. N Engl J Med. 2016;375(8):794-8. https://doi.org/10.1056/NEJMsr1606602

2. Hill JH, Solt C, Foster MT. Obesity associated disease risk: the role of inherent differences and location of adipose depots. Horm Mol Biol Clin Investig. 2018;33(2):20180012. https://doi.org/10.1515/hmbci-2018-0012

3. Christakoudi S, Tsilidis KK, Muller DC, Freisling H, Weiderpass E, Overvad K, et al. A body shape index (ABSI) achieves better mortality risk stratification than alternative indices of abdominal obesity: results from a large European cohort. Sci Rep. 2020;10(1):14541. https://doi.org/10.1038/s41598-020-71302-5.

4. Krakauer NY, Krakauer JC. A new body shape index predicts mortality Hazard independently of body mass index. PLoS One. 2012;7(7):e39504. https://doi.org/10.1371/journal.pone.0039504.

5. Krakauer NY, Krakauer JC. An anthropometric risk index based on combining height, weight, waist, and hip measurements. J Obes. 2016;2016: 1-9. https://doi.org/10.1155/2016/8094275.

6. Bertoli S, Leone A, Krakauer NY, Bedogni G, Vanzulli A, Redaelli VI, et al. Association of Body Shape Index (ABSI) with cardio-metabolic risk factors: a cross-sectional study of 6081 Caucasian adults. PLoS One. 2017;12(9): e0185013. https://doi.org/10.1371/journal.pone.0185013.

7. Christakoudi S, Tsilidis KK, Evangelou E, Riboli E. A body shape index (ABSI), hip index and risk of cancer in the UK Biobank cohort. Cancer Med. 2021; 10(16):5614-28. https://doi.org/10.1002/CAM4.4097.

8. UK Biobank Coordinating Centre; UK Biobank: Protocol for a large-scale prospective epidemiological resource. Protocol No: UKBB-PROT-09-06 (Main Phase); 21 March 2007 (amendment one final). URL: https://www.ukbioba nk.ac.uk/media/gnkeyh2q/study-rationale.pdf . Accessed 7 Sept 2021.

9. Sudlow C, Gallacher J, Allen N, Beral V, Burton P, Danesh J, et al. UK biobank: an open access resource for identifying the causes of a wide range 
of complex diseases of middle and old age. PLoS Med. 2015;12(3):e1001779. https://doi.org/10.1371/journal.pmed.1001779.

10. Christakoudi S, Evangelou E, Riboli E, Tsilidis KK. GWAS of allometric bodyshape indices in UK Biobank identifies loci suggesting associations with morphogenesis, organogenesis, adrenal cell renewal and cancer. Sci Rep. 2021;11(1):10688. https://doi.org/10.1038/s41598-021-89176-6.

11. Stark T, Walker B, Phillips JK, Fejer R, Beck R. Hand-held dynamometry correlation with the gold standard isokinetic dynamometry: a systematic review. PM R. 2011;3(5):472-9. https://doi.org/10.1016/j.pmrj.2010.10.025.

12. Borga M, West J, Bell JD, Harvey NC, Romu T, Heymsfield SB, et al. Advanced body composition assessment: from body mass index to body composition profiling. J Investig Med. 2018;66(5):1-9. https://doi.org/10.1136/jim-2018000722.

13. Stults-Kolehmainen MA, Stanforth PR, Bartholomew JB, Lu T, Abolt CJ, Sinha R. DXA estimates of fat in abdominal, trunk and hip regions varies by ethnicity in men. Nutr Diabetes. 2013;3(3):e64. https://doi.org/10.1038/nutd.2 013.5 .

14. West J, Dahlqvist Leinhard O, Romu T, Collins R, Garratt S, Bell JD, et al. Feasibility of MR-based body composition analysis in large scale population studies. PLoS One. 2016;11(9):e0163332. https://doi.org/10.1371/journal. pone.0163332.

15. Palmer BF, Clegg DJ. The sexual dimorphism of obesity. Mol Cell Endocrinol. 2015;402:113-9. https://doi.org/10.1016/..mce.2014.11.029.

16. Zheng D, Trynda J, Williams C, Vold JA, Nguyen JH, Harnois DM, et al. Sexual dimorphism in the incidence of human cancers. BMC Cancer. 2019; 19(1):684. https://doi.org/10.1186/s12885-019-5902-z.

17. Bradbury KE, Young HJ, Guo W, Key TJ. Dietary assessment in UK Biobank: an evaluation of the performance of the touchscreen dietary questionnaire. J Nutr Sci. 2018;7:e6. https://doi.org/10.1017/jns.2017.66.

18. StataCorp. Stata statistical software: release 13. College Station, TX: StataCorp LP; 2013.

19. R Core Team (2017). R: A language and environment for statistical computing. R Foundation for Statistical Computing, Vienna, Austria. URL https://www.r-project.org. Accessed 07 Sept 2021.

20. Bouchi R, Asakawa M, Ohara N, Nakano Y, Takeuchi T, Murakami M, et al. Indirect measure of visceral adiposity 'A body shape Index' (ABSI) is associated with arterial stiffness in patients with type 2 diabetes. BMJ Open Diabetes Res Care. 2016;4(1):e000188. https://doi.org/10.1136/bmjdrc-2015000188

21. Hoermann R, Fui MNT, Krakauer JC, Krakauer NY, Grossmann M. A body shape index (ABSI) reflects body composition changes in response to testosterone treatment in obese men. Int J Obes. 2019;43(11):2210-6. https://doi.org/10.1038/s41366-018-0311-y.

22. Krakauer NY, Krakauer JC. Association of Body Shape Index (ABSI) with hand grip strength. Int J Environ Res Public Health. 2020;17(18):6797. https://doi. org/10.3390/ijerph17186797.

23. Biolo G, Di Girolamo FG, Breglia A, Chiuc M, Baglio V, Vinci P, et al. Inverse relationship between "a body shape index" (ABSI) and fat-free mass in women and men: insights into mechanisms of sarcopenic obesity. Clin Nutr. 2015;34(2):323-7. https://doi.org/10.1016/j.clnu.2014.03.015.

24. Gomez-Peralta F, Abreu C, Cruz-Bravo M, Alcarria E, Gutierrez-Buey G, Krakauer NY, et al. Relationship between "a body shape index (ABSI)" and body composition in obese patients with type 2 diabetes. Diabetol Metab Syndr. 2018;10(1):21. https://doi.org/10.1186/s13098-018-0323-8.

25. Dhana K, Koolhaas CM, Schoufour JD, Rivadeneira F, Hofman A, Kavousi M, et al. Association of anthropometric measures with fat and fat-free mass in the elderly: the Rotterdam study. Maturitas. 2016;88:96-100. https://doi.org/1 0.1016/j.maturitas.2016.03.018

26. Sylow L, Tokarz VL, Richter EA, Klip A. The many actions of insulin in skeletal muscle, the paramount tissue determining glycemia. Cell Metab. 2021;33(4): 758-80. https://doi.org/10.1016/..cmet.2021.03.020.

27. Bouchard C, Tchernof A, Tremblay A. Predictors of body composition and body energy changes in response to chronic overfeeding. Int J Obes. 2014; 38(2):236-42. https://doi.org/10.1038/ijo.2013.77.

28. Kaul S, Rothney MP, Peters DM, Wacker WK, Davis CE, Shapiro MD, et al. Dual-energy X-ray absorptiometry for quantification of visceral fat. Obesity (Silver Spring). 2012;20(6):1313-8. https://doi.org/10.1038/oby.2011.393.

29. Sizoo D, de Heide LJM, Emous M, van Zutphen T, Navis G, van Beek AP. Measuring muscle mass and strength in obesity: a review of various methods. Obes Surg. 2021:31(1):384-93. https://doi.org/10.1007/s11695-02005082-2.
30. Messina C, Albano D, Gitto S, Tofanelli L, Bazzocchi A, Ulivieri FM, et al. Body composition with dual energy $X$-ray absorptiometry: from basics to new tools. Quant Imaging Med Surg. 2020;10(8):1687-98. https://doi.org/10.2103 7/qims.2020.03.02

31. Sun G, French CR, Martin GR, Younghusband B, Green RC, Xie YG, et al. Comparison of multifrequency bioelectrical impedance analysis with dualenergy X-ray absorptiometry for assessment of percentage body fat in a large, healthy population. Am J Clin Nutr. 2005;81(1):74-8. https://doi.org/1 0.1093/ajcn/81.1.74.

32. Johnson Stoklossa CA, Forhan M, Padwal RS, Gonzalez MC, Prado CM. Practical considerations for body composition assessment of adults with class II/III obesity using bioelectrical impedance analysis or dual-energy Xray absorptiometry. Curr Obes Rep. 2016;5(4):389-96. https://doi.org/10.1 007/s13679-016-0228-5.

33. Tinsley GM, Moore ML, Rafi Z, Griffiths N, Harty PS, Stratton MT, et al. Explaining discrepancies between Total and segmental DXA and BIA body composition estimates using Bayesian regression. J Clin Densitom. 2021; 24(2):294-307. https://doi.org/10.1016/j.jocd.2020.05.003.

34. Abar L, Vieira AR, Aune D, Sobiecki JG, Vingeliene S, Polemiti E, et al. Height and body fatness and colorectal cancer risk: an update of the WCRF-AICR systematic review of published prospective studies. Eur J Nutr. 2018;57(5): 1701-20. https://doi.org/10.1007/s00394-017-1557-1.

35. Silveira EA, Kliemann N, Noll M, Sarrafzadegan N, de Oliveira C. Visceral obesity and incident cancer and cardiovascular disease: an integrative review of the epidemiological evidence. Obes Rev. 2020;22(1):e13088. https://doi.org/10.1111/obr.13088.

36. He Q, Xia B, Liu A, Li M, Zhou Z, Cheung EC, et al. Association of body composition with risk of overall and site-specific cancers: a populationbased prospective cohort study. Int J Cancer. 2021;149(7):1435-47. https:// doi.org/10.1002/ijc.33697.

37. Ortega LS, Bradbury KE, Cross AJ, Morris JS, Gunter MJ, Murphy N. A prospective investigation of body size, body fat composition and colorectal Cancer risk in the UK Biobank. Sci Rep. 2017;7(1):17807. https://doi.org/10.1 038/s41598-017-17997-5.

38. Kadmiel M, Cidlowski JA. Glucocorticoid receptor signaling in health and disease. Trends Pharmacol Sci. 2013;34(9):518-30. https://doi.org/10.1016/j. tips.2013.07.003.

39. Pasquali R, Vicennati V, Cacciari M, Pagotto U. The hypothalamic-pituitaryadrenal axis activity in obesity and the metabolic syndrome. Ann N Y Acad Sci. 2006;1083(1):111-28. https://doi.org/10.1196/annals.1367.009.

40. Ruiz D, Padmanabhan V, Sargis RM. Stress, sex, and sugar: glucocorticoids and sex-steroid crosstalk in the sex-specific Misprogramming of metabolism. J Endocr Soc. 2020;4(8):bvaa087. https://doi.org/10.1210/jendso/bvaa087.

41. Holmäng A, Björntorp P. The effects of cortisol on insulin sensitivity in muscle. Acta Physiol Scand. 1992;144(4):425-31. https://doi.org/10.1111/j.174 8-1716.1992.tb09316.x

42. Reynolds RM, Chapman KE, Seckl JR, Walker BR, McKeigue PM, Lithell HO. Skeletal muscle glucocorticoid receptor density and insulin resistance. JAMA. 2002;287(19):2505-6. https://doi.org/10.1001/jama.287.19.2505.

43. Delivanis DA, Iñiguez-Ariza NM, Zeb MH, Moynagh MR, Takahashi N, McKenzie TJ, et al. Impact of hypercortisolism on skeletal muscle mass and adipose tissue mass in patients with adrenal adenomas. Clin Endocrinol. 2018;88(2):209-16. https://doi.org/10.1111/cen.13512.

44. Hong N, Lee J, Ku CR, Han K, Lee CR, Kang SW, et al. Changes of computed tomography-based body composition after adrenalectomy in patients with endogenous hypercortisolism. Clin Endocrinol. 2019;90(2):267-76. https:// doi.org/10.1111/cen.13902.

45. Vierhapper H, Nowotny P, Waldhäusl W. Production rates of testosterone in patients with Cushing's syndrome. Metabolism. 2000;49(2):229-31. https:// doi.org/10.1016/s0026-0495(00)91429-x.

46. Contreras LN, Masini AM, Danna MM, Kral M, Bruno OD, Rossi MA, et al. Glucocorticoids: their role on gonadal function and LH secretion. Minerva Endocrinol. 1996;21(2):43-6.

47. Lima TFN, Nackeeran S, Rakitina E, Lima GFN, Arora H, Kargi AY, et al. Association of Leptin with Total and free testosterone: results from the National Health and nutrition examination surveys. Androg Clin Res Ther. 2020;1(1):94-100. https://doi.org/10.1089/andro.2020.0007.

48. Diago-Galmés A, Guillamón-Escudero C, Tenías-Burillo JM, Soriano JM, Fernández-Garrido J. Salivary testosterone and cortisol as biomarkers for the diagnosis of sarcopenia and Sarcopenic obesity in community-dwelling older adults. Biology. 2021;10(2):93. https://doi.org/10.3390/biology10020093. 
49. Sinha-Hikim I, Cornford M, Gaytan H, Lee ML, Bhasin S. Effects of testosterone supplementation on skeletal muscle fiber hypertrophy and satellite cells in community-dwelling older men. J Clin Endocrinol Metab. 2006:91(8):3024-33. https://doi.org/10.1210/jc.2006-0357.

50. Allan CA, Strauss BJ, Burger HG, Forbes EA, McLachlan RI. Testosterone therapy prevents gain in visceral adipose tissue and loss of skeletal muscle in nonobese aging men. J Clin Endocrinol Metab. 2008;93(1):139-46. https:// doi.org/10.1210/jc.2007-1291.

51. Sebo ZL, Rodeheffer MS. Testosterone metabolites differentially regulate obesogenesis and fat distribution. Mol Metab. 2021:44:101141. https://doi. org/10.1016/j.molmet.2020.101141.

52. Kirschner MA, Samojlik E, Drejka M, Szmal E, Schneider G, Ertel N. Androgenestrogen metabolism in women with upper body versus lower body obesity. J Clin Endocrinol Metab. 1990;70(2):473-9. https://doi.org/10.1210/ jcem-70-2-473.

53. Elbers JMH, Asscheman H, Seidell JC, Gooren LJG. Effects of sex steroid hormones on regional fat depots as assessed by magnetic resonance imaging in transsexuals. Am J Physiol Endocrinol Metab. 1999;276(2):E317E25. https://doi.org/10.1152/ajpendo.1999.276.2.E317.

54. Escobar-Morreale HF, Santacruz E, Luque-Ramírez M, Botella Carretero II. Prevalence of 'obesity-associated gonadal dysfunction' in severely obese men and women and its resolution after bariatric surgery: a systematic review and meta-analysis. Hum Reprod Update. 2017;23(4):390-408. https:// doi.org/10.1093/humupd/dmx012.

55. Coburn SB, Stanczyk FZ, Falk RT, McGlynn KA, Brinton LA, Sampson J, et al. Comparability of serum, plasma, and urinary estrogen and estrogen metabolite measurements by sex and menopausal status. Cancer Causes Control. 2019;30(1):75-86. https://doi.org/10.1007/s10552-018-1105-1.

56. Park Y-M, Erickson C, Bessesen D, Van Pelt RE, Cox-York K. Age- and menopause-related differences in subcutaneous adipose tissue estrogen receptor mRNA expression. Steroids. 2017;121:17-21. https://doi.org/10.101 6/j.steroids.2017.03.001.

57. Lizcano F, Guzman G. Estrogen deficiency and the origin of obesity during menopause. Biomed Res Int. 2014;2014:1-11. https://doi.org/10.1155/2014/ 757461

58. Davis KE, Neinast DM, Sun K, Skiles MW, Bills DJ, Zehr AJ, et al. The sexually dimorphic role of adipose and adipocyte estrogen receptors in modulating adipose tissue expansion, inflammation, and fibrosis. Mol Metab. 2013;2(3): 227-42. https://doi.org/10.1016/j.molmet.2013.05.006.

59. Quinn MA, Xu X, Ronfani M, Cidlowski JA. Estrogen deficiency promotes hepatic steatosis via a glucocorticoid receptor-dependent mechanism in mice. Cell Rep. 2018;22(10):2690-701. https://doi.org/10.1016/j.celrep.2018. 02.041 .

60. Gambacciani M, Ciaponi M, Cappagli B, Piaggesi L, De Simone L, Orlandi R, et al. Body weight, body fat distribution, and hormonal replacement therapy in early postmenopausal women. J Clin Endocrinol Metab. 1997; 82(2):414-7. https://doi.org/10.1210/jcem.82.2.3735.

61. Christakoudi S, Pagoni P, Ferrari P, Cross AJ, Tzoulaki I, Muller DC, et al. Weight change in middle adulthood and risk of cancer in the European prospective investigation into Cancer and nutrition (EPIC) cohort. Int J Cancer. 2021;148(7):1637-51. https://doi.org/10.1002/ijc.33339.

62. Sato R, Suzuki T, Katayose Y, Miura K, Shiiba K, Miki Y, et al. Aromatase in colon carcinoma. Anticancer Res. 2012;32(8):3069-75.

63. Chen J, Iverson D. Estrogen in obesity-associated colon cancer: friend or foe? Protecting postmenopausal women but promoting late-stage colon cancer. Cancer Causes Control. 2012;23(11):1767-73. https://doi.org/10.1007/ s10552-012-0066-Z.

64. Sidler D, Renzulli P, Schnoz C, Berger B, Schneider-Jakob S, Flück C, et al. Colon cancer cells produce immunoregulatory glucocorticoids. Oncogene. 2011;30(21):2411-9. https://doi.org/10.1038/onc.2010.629.

65. Lointier P, Wildrick DM, Boman BM. The effects of steroid hormones on a human colon cancer cell line in vitro. Anticancer Res. 1992;12(4):1327-30.

66. Stults-Kolehmainen MA, Stanforth PR, Bartholomew JB. Fat in android, trunk, and peripheral regions varies by ethnicity and race in college aged women. Obesity (Silver Spring). 2012;20(3):660-5. https://doi.org/10.1038/oby.2011.300.

67. Fry A, Littlejohns TJ, Sudlow C, Doherty N, Adamska L, Sprosen T, et al. Comparison of sociodemographic and health-related characteristics of UK Biobank participants with those of the general population. Am J Epidemiol. 2017;186(9):1026-34. https://doi.org/10.1093/aje/kwx246.

\section{Publisher's Note}

Springer Nature remains neutral with regard to jurisdictional claims in published maps and institutional affiliations.

\section{Ready to submit your research? Choose BMC and benefit from:}

- fast, convenient online submission

- thorough peer review by experienced researchers in your field

- rapid publication on acceptance

- support for research data, including large and complex data types

- gold Open Access which fosters wider collaboration and increased citations

- maximum visibility for your research: over $100 \mathrm{M}$ website views per year

At BMC, research is always in progress.

Learn more biomedcentral.com/submissions 